\title{
Barriers and facilitators perceived by people with bipolar disorder for the practice of exercise: a qualitative study
}

\author{
Barreiras e facilitadores percebidos por pessoas com transtorno bipolar para a \\ prática de exercício físico: um estudo qualitativo
}

\author{
Caroline Silveira Pereira, (10) Carolina Stopinski Padoan, Lucas França Garcia, (1) Lucas Patusco, Pedro V. S. Magalhães (1)
}

\begin{abstract}
Introduction: Exercising regularly has benefits for people with bipolar disorder. Nevertheless, as a group, these patients tend to be less physically active than the general population and little is known from the viewpoint of the patients about the barriers and facilitators to such a practice.

Objective: To know the barriers and facilitators perceived by people with bipolar disorder for the practice of exercise.

Methods: This study had a descriptive, qualitative, exploratory nature. The investigation method used for data collection was a semi-structured in-depth interview, using grounded theory as theoretical framework.

Results: The data analysis generated two main areas of interest: adherence to regular physical exercise (barriers and facilitators) and the participants' exercise history and perception of disease management, as described below. The main findings were: most of our sample did not exercise regularly, nor knew how exercise can positively influence their disorder; with regard to adherence to physical exercise, the presence of symptoms and stigma were the most important barriers to the practice of physical exercise. Social support, especially from family and friends, could be a facilitator to the practice of exercise.

Conclusions: Even considering the limitations for generalization of qualitative and exploratory studies, understanding perceived barriers and facilitators for the practice of exercise among people who suffer with bipolar disorder may contribute to the promotion of activities in which people with mental illness can participate. Keywords: Mood disorders, exercise, walking.
\end{abstract}

\section{Resumo}

Introdução: A prática regular de exercício físico tem benefícios para pessoas com transtorno bipolar. No entanto, como grupo, esses pacientes tendem a ser mais sedentários do que a população geral, e pouco se sabe do ponto de vista dos pacientes sobre as barreiras e facilitadores para tal prática.

Objetivo: Conhecer as barreiras e facilitadores percebidos por pessoas com transtorno bipolar para a prática de exercício.

Métodos: Este foi um estudo descritivo, qualitativo e exploratório. O método de investigação utilizado na coleta de dados foi entrevista semiestruturada em profundidade, segundo a grounded theory.

Resultados: A análise dos conteúdos que surgiram nas entrevistas gerou duas principais áreas de interesse: adesão ao exercício físico regular (barreiras e facilitadores) e a história de exercícios dos participantes e a percepção do manejo da doença. Os principais achados foram: a maioria da nossa amostra não se exercitava regularmente, nem mesmo sabia como a prática regular podia influenciar positivamente sua doença; em relação à adesão ao exercício físico, a presença dos sintomas e do estigma foram as barreiras mais importantes para praticar o exercício físico. O apoio social, especialmente da família e dos amigos, pode ser um facilitador da adesão ao exercício.

Conclusões: Apesar das limitações de um estudo qualitativo e exploratório, conhecer as barreiras e os facilitadores percebidos para a prática de exercício entre pessoas que sofrem de transtorno bipolar pode facilitar a promoção de atividades onde essas pessoas possam participar e se beneficiar efetivamente. Descritores: Transtornos do humor, exercício, caminhada.

Universidade Federal do Rio Grande do Sul (UFRGS), Porto Alegre, RS, Brazil.

This manuscript was based on the academic Master's dissertation entitled "Barriers and facilitators perceived by people with bipolar disorder for the practice of exercise," presented in 2016 at Universidade Federal do Rio Grande do Sul (UFRGS), Porto Alegre, RS, Brazil.

Submitted Jun 08 2017, accepted for publication May 102018.

Suggested citation: Pereira CS, Padoan CS, Garcia LF, Patusco L, Magalhães PVS. Barriers and facilitators perceived by people with bipolar disorder for the practice of exercise: a qualitative study. Trends Psychiatry Psychother. 2019;41(1):1-8. http://dx.doi.org/10.1590/2237-6089-2017-0069 


\section{Introduction}

Regular practice of exercise has the potential to improve the quality of life of people with bipolar disorder. This involves behavioral changes and contributes to improving issues associated with the disease, such as low self-esteem and social isolation, providing opportunities for a favorable environment for the individual to interact, create links and regain their autonomy and self-confidence. ${ }^{1-4}$ Exercising also has an impact on physical health outcomes. ${ }^{5}$ Moreover, this practice can contribute to mood stability. ${ }^{6,7}$ Exercise has the potential to help individuals structure their lives, providing routine and thus contributing to mood regulation. ${ }^{8}$ Specifically in bipolar disorder, there is evidence that exercise can be neuroprotective, i.e., exercise can improve cognitive function and has been linked to the increased expression of brain-derived neurotrophic factor (BDNF). ${ }^{9-11}$ Exercise can also be a great ally in lowering the clinical and social burden associated with bipolar disorder. It is associated with weight loss and can control the body fat percentage, decreasing the risk of cardiovascular disease, controlling blood pressure, glucose, and decreasing insulin resistance, thus promoting better health in general. ${ }^{12-14}$ This point is of extreme importance, since the prevalence of clinical comorbidities in this population is very high, with more than half of participants in some studies having at least one chronic medical comorbidity. ${ }^{15,16}$

Since most of the socioeconomic burden - and costs - related to bipolar disorder is associated with these comorbidities, there is interest in interventions that have an impact on other outcomes, not only symptoms. The disorder and aggregate burdens cause a drop in productivity, with negative impacts on social relationships, work and quality of life. ${ }^{17,18}$ Furthermore, these comorbidities increase the risk of premature mortality in a population that dies earlier when compared to the general population. ${ }^{19}$ This implies higher public health costs, since people with bipolar disorder require treatment also for the physical chronic diseases to which they are susceptible. ${ }^{20}$ Despite these benefits, people with mental disorders tend to be less physically active than the general population. ${ }^{21}$ Therefore, it is important to stimulate effective approaches that are able to prevent and treat these comorbidities, substantially reducing the economic burden and functional wear related to this condition. In this process, physical exercise is an important ally as it helps in the long term and can be cost-effective. ${ }^{22,23}$ This requires greater attention to enable activities that these people can participate in and benefit from.

For these interventions to be effective, one should know the barriers that are perceived by these people and prevent them from adopting healthy behaviors. Barriers are potential obstructions that may limit or prevent the beginning, maintenance or continuation of participation in an activity. ${ }^{24}$ Moreover, we should also know the facilitators perceived by these individuals as contributing to the practice of regular physical exercise. ${ }^{25}$ Facilitators are factors that support the inclusion of the subject in some activity. ${ }^{26}$ However, studies on the perception of barriers and facilitators for physical exercise in people with severe mental disorders are scarce, and tend to come from high-income countries. ${ }^{8,27-29}$ Thus, the aim of this study was to understand the perceptions of people with bipolar disorder on barriers and facilitators to the regular practice of physical exercise. For such, we report here the results of a qualitative study involving people with bipolar disorder receiving treatment at a tertiary outpatient clinic. This method allows us to approach the experiences of the participants, and the meanings they have, from their own point of view. ${ }^{30}$

\section{Methods}

\section{Design}

This study had a descriptive, qualitative, exploratory nature. A few previous international studies addressing the perceptions of patients with mental disorders about barriers and facilitators to exercise training have used this method. 8,29,31,32 According to the American Psychiatric Association, ${ }^{33}$ research protocols involving patients with mental disorders should prioritize the perspectives of these patients in order to produce new knowledge for the population under study. Thus, we can describe and understand the complexity of the phenomenon studied from the perspective of the participants and the meanings that the phenomenon has to them. ${ }^{34,35}$

The article followed the recommendations of the consolidated criteria for reporting qualitative research (COREQ). ${ }^{36}$

\section{Instrument}

The investigation method used for data collection was a semi-structured in-depth interview to conform with the purpose of the research, i.e., approaching the experiences and perceptions of participants towards physical exercise. ${ }^{34,37}$ Through open questions and other discussions that emerged, we sought to extract detailed stories on the subject under study. In addition, in-depth interviews allow a deepening in personal and social issues of the subject, reconstructing their perceptions and experiences related to the phenomenon under study. ${ }^{30} \mathrm{~A}$ semi-structured interview guide was developed to allow the participants to tell their stories 
openly, in their own words. This script contained four areas of interest discussed a priori, and according to the literature: physical exercise (know the history of exercise in person), personal health care (associations of ideas with health care), barriers and facilitators to the practice of exercise. Pilot interviews with volunteers were carried out, in order to verify the adequacy of the open questions. The individual interviews took an average of 30 minutes and were conducted by a master's student, physical education teacher (CSPe), with basic training in conducting semi-structured interviews and a previous affiliation with the service as mental health resident. She was trained in the principles of in-depth interviewing by two researchers with previous experience, a sociologist (LFG) and a psychologist (CSPa). The researcher maintained a welcoming attitude, favoring the creation of a peaceful environment, prioritizing authentic lines. All interviews were audio-recorded and later transcribed verbatim. The coding scheme was developed by two researchers (CSPe and LFG) during the analysis of data. Due to the dynamics of outpatient and hospitalization settings, it was not possible to gather a feedback from the patients on the findings.

\section{Participants}

Adult patients with a diagnosis of bipolar disorder, attending the Bipolar Disorders Program (Programa de Atendimento do Transtorno do Humor Bipolar [PROTAHBI]) of Hospital de Clínicas de Porto Alegre (HCPA) and admitted to the psychiatric inpatient unit of the hospital were invited to participate. Diagnosis of bipolar disorder is confirmed upon admission to the programs by the attending clinicians, using criteria from the Diagnostic and Statistical Manual of Mental Disorders, 5th edition (DSM-5). For outpatients, the invitation was made by phone calls; inpatients were invited personally. Invitations were made with the consent of the team responsible for the patients. Patients were required to be euthymic and not suffering from psychosis or suicidal ideation. Thus, all included patients were deemed able to understand and to give their consent to participate in the study.

The sampling method used was purposive sampling. ${ }^{38}$ In purposive sampling, researchers select those participants they deem more adequate for the study, i.e., persons with particular characteristics willing to provide information relevant to the study on the basis of their knowledge and experience. It is a non-probabilistic sampling method often employed in qualitative research. The theoretical sample comprised individuals who could represent the research question, i.e., patients who were engaged in some way in the treatment of their disease. Using this method, sample size definition is given by the saturation of the results found in the in-depth interviews. Saturation is a standard criterion for qualitative studies to evaluate when the data gathered will no longer generate new insights, i.e., the point in the research when all the concepts are well defined and explained and no further analytical constructs can be identified, thus causing the data collection to stop. In this process, data collection and analysis of results occurs simultaneously while new data relevant to the study is generated. ${ }^{37-41}$

All patients were informed about the objectives, as well as the risks and benefits of participating in this study and signed a consent form. The study followed Resolution no. 466/2012 and Helsinki Declaration guidelines with regard to the ethical principles related to research with human subjects. The research was approved by the research ethics committee of Hospital de Clínicas de Porto Alegre.

\section{Data analysis}

Grounded theory was used for qualitative data analysis. ${ }^{40}$ This technique is suitable for the construction of knowledge in areas where little is known about a phenomenon, as is the case of our research question. Its main objective is to develop innovative theories based on various individual cases, from the analysis and interpretation of data collected in the interviews, coming from the complex experiences of the subject in its social context. ${ }^{30,40}$ According to this theory, the analysis of the data does not start with preconceived theories or a literature review. Rather, it involves constructing a theory that is able to increase the understanding of a social and/or psychological phenomenon through data analysis. ${ }^{42}$ Moreover, ground theory makes it possible to capture subtleties and quirks, providing a new and creative perspective on the phenomenon under study. The difference between this technique and other qualitative analysis methods is its innovative approach, able to seek new knowledge instead of testing theories, thus meeting the needs of the present project.

Our analysis started with the answers of each respondent and had three specific stages, in accordance with the model proposed by Fassinger ${ }^{30}$ : open coding, axial coding and selective coding. Qualitative analysis was performed by two encoders (CSPe and LFG), with the assistance of NVivo version 10, licensed by Universidade Federal do Rio Grande do Sul. ${ }^{43}$ The software was used to store the audio and transcripts of the interviews, to select text fragments for analysis, to create thematic areas and codes and organize fragments according to specific topics, and to rearrange the interviews in accordance with the code established by comparison analysis. 


\section{Results}

Twenty-three people with a diagnosis of bipolar disorder participated in this study. Participants were 9 men and 14 women, with ages between 19 and 66 years. Table 1 shows a description of the participants. Twenty-one patients reported that they did not exercise regularly.

Data analysis and coding generated two main areas of interest: 1) participants' exercise history and perception of disease management; and 2) adherence to regular physical exercise (barriers and facilitators). These data are shown in Table 2.

\section{Practice and history of exercise}

Only two patients practiced exercise regularly at the time of the interview, but all said they had practiced some form of physical exercise at some point in their lifetime. In most cases, this practice was attributed to physical education in school. The types of exercise

Table 1 - Characteristics of the study sample

\begin{tabular}{|c|c|c|c|c|c|c|}
\hline Participant & Gender & Age & $\begin{array}{l}\text { Family income } \\
\text { (reais/month) }\end{array}$ & Education level & Occupation & Marital status \\
\hline E01 & $\mathrm{F}$ & 29 & 1,500 & Incomplete higher education & Student & Married \\
\hline E02 & M & 19 & 2,380 & Incomplete high school & Student & Single \\
\hline E03 & M & 41 & 1,000 & High school & Student & Single \\
\hline E04 & $\mathrm{F}$ & 55 & 2,000 & High school & Retired & Married \\
\hline E05 & $\mathrm{F}$ & 38 & 4,000 & Incomplete higher education & Employee & Separated \\
\hline E06 & $\mathrm{F}$ & 51 & 723 & High school & On disability & Married \\
\hline E07 & M & 30 & 1,000 & Primary education & On disability & Married \\
\hline E08 & $\mathrm{F}$ & 43 & 820 & Incomplete primary education & On disability & Married \\
\hline E09 & M & 44 & 847 & High school & On disability & Single \\
\hline E10 & $\mathrm{F}$ & 47 & 2,000 & High school & On disability & Married \\
\hline E11 & M & 31 & 5,000 & Incomplete higher education & Employee & Single \\
\hline E12 & $\mathrm{F}$ & 55 & 1,800 & High school & On disability & Married \\
\hline E13 & $\mathrm{F}$ & 51 & 2,800 & High school & Employee & Single \\
\hline E14 & $\mathrm{F}$ & 57 & 724 & Incomplete primary education & On disability & Widowed \\
\hline E15 & M & 25 & Not mentioned & Incomplete high school & On disability & Single \\
\hline E16 & M & 42 & Not mentioned & High school & Employed & Single \\
\hline E17 & $\mathrm{F}$ & 44 & 4,000 & Incomplete primary education & On disability & Married \\
\hline E18 & $\mathrm{F}$ & 66 & 1,500 & Incomplete primary education & Employee & Separated \\
\hline E19 & $\mathrm{F}$ & 60 & 724 & Incomplete high school & On disability & Separated \\
\hline E20 & M & 59 & 3,700 & College & On disability & Married \\
\hline E21 & $\mathrm{F}$ & 30 & 1,500 & Incomplete higher education & On disability & Single \\
\hline E22 & $\mathrm{F}$ & 37 & Not mentioned & College & On disability & Married \\
\hline E23 & M & 19 & Not mentioned & Incomplete high school & Student & Single \\
\hline
\end{tabular}

Table 2 - Participants' exercise history and perception of disease management

\begin{tabular}{ll}
\hline Topic & Example \\
\hline $\begin{array}{l}\text { Practice and history } \\
\text { of exercise }\end{array}$ & "I don't [practice exercise] regularly for now." (E3) \\
& "Oh, I practiced [exercise] in high school and after I got sick I did a year of walking." (E10) \\
& "Just walking, but nothing regular." (E3) \\
& "The easiest and most I do is walking." (E21) \\
Disease management & "Taking medicine, participating in CAPS." (E21) \\
& "Oh I try to eat well, eating always comes first. I eat plenty of fruit, vegetables, so they are always on the \\
& menu." (E10) \\
& "No, never. Nobody suggested I do it. It is the first time I hear about it for bipolar disorder." (E4) \\
& "Because the doctor said I was overweight." (E9)
\end{tabular}


practiced were also very related to school physical education, such as volleyball and soccer. Walking was frequently mentioned, justified by the ease of access and no cost.

Regarding motivation, the majority of the respondents attributed it to personal and aesthetic gains. At this point, it is worth noting that three patients associated manic symptoms with the motivation to practice exercise.

\section{Disease management}

Most respondents associated health care with the regular use of medication. In addition, many reported that they seek to maintain a healthy diet and engage in activities that make them feel good, like reading, watching television programs and participating in therapeutic workshops at centers for psychosocial care (Centro de Atenção Psicossocial [CAPS]). However, exercise training was rarely associated with the treatment for bipolar disorder. The only benefit associated was weight loss, citing the promotion of self-esteem as a motivating factor to maintain an activity. In addition, most of the sample reported never having received any advice of health professionals to practice exercise to assist in their treatment for bipolar disorder.

\section{Barriers}

Respondents reported social stigma, disease symptoms such a depressive symptoms, and sometimes the fear of presenting any symptoms as significant barriers to the practice of exercise. The following factors were also mentioned to worsen adherence: associated physical comorbidities, lack of self-esteem, lack of a motivator, lack of time, often associated with the demands of work or home care, the financial situation and difficulty accessing free activities or nearby places of residence, and the weather, especially in the winter (Table 3 ).

Table 3 - Adherence to regular physical exercise (barriers and facilitators)

\begin{tabular}{|c|c|}
\hline Topic & Example \\
\hline \multirow[t]{12}{*}{ Barriers } & "The problem, you know, is that you are seen differently." (E8) \\
\hline & $\begin{array}{l}\text { "I am afraid to go to the gym and, let's say, I think there is something wrong about someone, it's not going to work, } \\
\text { it's going to be a problem." (E4) }\end{array}$ \\
\hline & $\begin{array}{l}\text { "Oh there are days when I get up and I'm nauseous, you know, I can't do anything at home, I think it's because of } \\
\text { the illness as well." (E10) }\end{array}$ \\
\hline & $\begin{array}{l}\text { "For me to go downtown, only if I go with someone, alone I cannot. Then I lost my autonomy and this is bad. Then } \\
\text { how could I do a physical activity elsewhere?" (E21) }\end{array}$ \\
\hline & $\begin{array}{l}\text { "To start with I'm ashamed to go to the gym, I do not like it [...] I do not like to expose myself. I do not like to be } \\
\text { looked at too much, I get upset. Usually you go to these places, you're cute and you have friends, you are not an old } \\
\text { fat lady, so I avoid it." (E4) }\end{array}$ \\
\hline & "I had no incentive." (E8) \\
\hline & "The lack of courage to start, depends on the person, the instructor." (E12) \\
\hline & "There was a time I was working and then I did not have time." (E21) \\
\hline & "I lack financial conditions, like clothing. Even for me to wear on a daily basis." (E7) \\
\hline & $\begin{array}{l}\text { "And where I live there is nothing close available [...]. Unfortunately, at least here, there are not many places that } \\
\text { you have access to do it." (E8) }\end{array}$ \\
\hline & "When it is cold it is more difficult to walk in the street." (E9) \\
\hline & $\begin{array}{l}\text { "I've always liked exercise, but everything I start I do not end because of depression, and from there the depression } \\
\text { would 'catch' me." (E5) }\end{array}$ \\
\hline \multirow[t]{5}{*}{ Facilitators } & $\begin{array}{l}\text { "If I had someone to tell me, 'hey, let's go and I'll go with you', I would go for sure. Now, if you expect me to go, it's } \\
\text { hard." (E8) }\end{array}$ \\
\hline & $\begin{array}{l}\text { "If I retired, my income would increase and I would be able to support myself, get my bills on time, be able to } \\
\text { purchase some clothes, then I think I would exercise." (E7) }\end{array}$ \\
\hline & "I think only time and disposition." (E1) \\
\hline & $\begin{array}{l}\text { "I was walking in a park close to home and then started to walk in a square near there, around the square, which } \\
\text { was easier and closer." (E9) }\end{array}$ \\
\hline & "When the gym here at the hospital opened, I applied." (E13) \\
\hline
\end{tabular}




\section{Facilitators}

Issues cited as barriers could also be facilitators of adherence to exercise training. The presence of social support (family member or friend) to enter and remain in practice, a more favorable financial position to allow paying for a gym or other activity, time available for practice and access to places that are free or near the individuals' residences, as well as a more favorable climate, were all cited as facilitators (Table 3 ).

\section{Discussion}

This study sought to know the perceptions of people with bipolar disorder regarding health care and barriers and facilitators for the regular practice of physical exercise. Few participants reported exercising and also few knew about its health benefits or effects on bipolar disorder.

The lack of knowledge and health care provider recommendation for physical exercise as a tool in the treatment of bipolar disorder emerged as a barrier. From the interviews, it was possible to conclude that when patients have free time, other activities are prioritized, causing the premature abandonment of activity. In a phenomenological qualitative analysis about exercise experiences among people with bipolar disorder, Wright et al. ${ }^{8}$ found the lack of knowledge of patients about the issues related to exercise and health as one of the barriers. In an exploratory qualitative study, ${ }^{29}$ patients reported that they would like to receive relevant guidelines in order to have guidance on how to perform an activity. These issues could be minimized by health professionals that assess physical activity level as a part of routine assessment. This could be an opportunity of playing a guiding role, clarifying about the benefits and encouraging the participation of these patients in some practice. ${ }^{44}$

Issues closely linked to bipolar disorder were also cited as barriers. In the patients' reports, stigma was a perception of patients, affecting how they see themselves, the world around them and the disease itself. As reported by McDevitt et al., ${ }^{29}$ these people are uncomfortable to attend different social places, and are afraid to show any symptoms of the disease and thus be identified and labeled as people with some mental problem. Therefore, they anticipate rejection and, to avoid embarrassment, many develop social isolation as a protection strategy. This barrier contributes to a lower engagement of subjects in the treatment. ${ }^{45}$

Symptoms of the disease, especially depressive symptoms, were also described as a barrier. When comparing the levels of physical activity among individuals with bipolar disorder, major depression and no diagnosis of mental disorder, Cairney et al. ${ }^{46}$ found that mood episodes in bipolar disorder interfere and can interrupt regular exercise. Patients interviewed by Wright et al. ${ }^{8}$ reported that in periods of altered mood, if there is not someone to monitor the practice of exercise, it hardly happens. Similar results were found by Ussher et al. ${ }^{28}$ in a cross-sectional study with patients with mental disorders receiving in-hospital and outpatient treatment. Through a structured questionnaire, those people reported that although they believed in the benefits of exercise, they felt incapable of exercising during depressive episodes and without the support of a family member or friend. Medication effects, particularly sedation and weight gain, were described by our respondents as barriers, as also found in Roberts \& Baley. ${ }^{27}$ When conducting a narrative synthesis of studies that address barriers and facilitators to exercise, the researchers found that medication effects were among the main potential barriers. The participants in the focus groups conducted by McDevitt et al. ${ }^{29}$ also identified sedation and weight gain as effects of the medication and, consequently, factors that influence the practice of some exercise. However, patients generally did not attribute their greatest difficulties to the practice of exercise to the disease itself, but rather to the disability that accompanies it.

Socioeconomic aspects were also considered barriers to physical exercise. Our reports corroborate the findings of Roberts \& Bailey, ${ }^{27}$ suggesting that poor living conditions and unemployment inhibit insertion in an activity. In addition, safety issues emerged, just as in the study conducted by McDevitt et al., ${ }^{29}$ which showed that people with mental disorders may be more susceptible to risks in places where crime is higher. When alone in the streets, they feel anxious and intimidated.

Finally, a regional issue often cited by the participants was the weather, especially in the winter, dominated by cold and rain. People who carry out activity in the open air are directly affected by this and must stop their practice. This point highlights the importance of providing activities in public places, protected from severe weather and available in suburbs.

Our respondents also mentioned factors that could facilitate their insertion in an exercise program. Among them, relying on social support was mentioned as relevant to deciding to start and keep an activity. Also with regard to social support, the ability to get along with people and the availability of spaces within the community play equally important roles in the initiative to introduce the exercise into one's routine. In studies conducted by McDevitt et al., ${ }^{29}$ Roberts and Baley, ${ }^{27}$ and Wright et al., ${ }^{8}$ participants also revealed that they 
felt more encouraged in the company of someone else, pointing to social network as a facilitator. The possibility to perform exercise at appropriate locations, available in suburbs and preferably targeted at lower-income populations, was often mentioned by respondents as a facilitator. Similarly to the participants studied by Graham et al., ${ }^{47}$ our respondents perceived that ease of access could cause a change in lifestyle.

Although most were not practicing at the moment of the interview, the patients clearly indicated walking as the preferred and more feasible type of exercise. Among other benefits, they cited the economic advantage and the possibility of interacting with their social environment while also allowing the presence of family and friends in the activity and consequently in their treatment. As we have seen in the most vulnerable groups, accessibility is one of the environmental factors that can hamper or promote their integration in an activity. This is an important advantage of walking, which becomes a democratic and relevant ally in health care, because it can reach a large number of people from different places and financial situations, promoting healthy habits and preventing diseases. ${ }^{48}$ It appears relevant to mention that the practice of walking, despite offering modest increases in activity levels, can generate clinically significant health benefits. ${ }^{49}$ There is evidence that when performed at least at moderate-intensity level, and in as many days of the week as possible, walking can reduce the risk of developing chronic diseases, improve socialization and decrease treatment expenses. ${ }^{50}$

Relevant limitations of this study include the inability to generalize the results, because the methodology enables creating innovative hypotheses and theories on the subject for the study population, but not extrapolating the data. However, qualitative studies may be more sensitive to locally relevant issues, especially considering a population of considerably low socioeconomic status - in need of specialized treatment at a tertiary care facility, indicating substantial severity and disability -, living in a Brazilian capital, and their specific needs. Despite this limitation, the study provides relevant hypotheses as to the reasons for physical inactivity, based on the participants' own experiences and their meanings. Confirmation of these findings in population-based studies should reinforce the need for research on ways to remove barriers and provide potential solutions for the practice of exercise by this population.

Public policies that target people with severe and chronic mental illness, encouraging the regular practice of physical exercise, are necessary. This study offers insights into possible avenues of inquiry to address this issue. From the patients' responses, one reasonable recommendation would be the promotion of walking groups, but guided physical exercise promoted by health institutions and possibly held where patients receive their treatment also appears logical. Both these approaches can be formally tested. But perhaps a first and fundamental barrier is the need for information about the benefits of exercise. This suggests that there is a need for better clarification and dissemination of the potential benefits of exercise both among patients and health care professionals.

\section{Acknowledgements}

This study received funding from Fundo de Incentivo à Pesquisa e Eventos - Hospital de Clínicas de Porto Alegre (FIPE-HCPA).

\section{Disclosure}

No conflicts of interest declared concerning the publication of this article.

\section{References}

1. Mason OJ, Holt R. Mental health and physical activity interventions: a review of the qualitative literature. J Ment Health. 2012;21:27484.

2. Richardson CR, Faulkner G, McDevitt J, Skrinar GS, Hutchinson DS, Piette JD. Integrating physical activity into mental health services for persons with serious mental illness. Psychiatr Serv. 2005; 56:324-31.

3. Quirk H, Crank H, Harrop D, Hock E, Copeland R. Understanding the experience of initiating community-based physical activity and social support by people with serious mental illness: a systematic review using a meta-ethnographic approach. Syst Rev. 2017;6:214.

4. Vancampfort D, Van Damme T, Probst M, Firth J, Stubbs B, Basangwa D, et al. Physical activity is associated with the physical, psychological, social and environmental quality of life in people with mental health problems in a low resource setting. Psychiatry Res. 2017;258:250-4.

5. Hearing CM, Chang WC, Szuhany KL, Deckersbach T, Nierenberg $A A$, Sylvia LG. Physical exercise for treatment of mood disorders: a critical review. Curr Behav Neurosci Rep. 2016;3:350-9.

6. Bowen R, Balbuena L, Baetz M, Schwartz L. Maintaining sleep and physical activity alleviate mood instability. Prev Med (Baltim). 2013;57:461-5.

7. Department of Health. Technical Report - Physical activity guidelines in the UK: review and recommendations. London: Loughborough University; 2010. https://assets.publishing.service. gov.uk/government/uploads/system/uploads/attachment_data/ file/213743/dh_128255.pdf

8. Wright K, Armstrong T, Taylor A, Dean S. 'It's a double edged sword': a qualitative analysis of the experiences of exercise amongst people with bipolar disorder. J Affect Disord. 2012;136:634-42.

9. Fernandes BS, Gama CS, Ceresér KM, Yatham LN, Fries GR, Colpo $G$, et al. Brain-derived neurotrophic factor as a state-marker of mood episodes in bipolar disorders: a systematic review and meta-regression analysis. J Psychiatr Res. 2011;45:995-1004.

10. de Sá Filho AS, de Souza Moura AM, Lamego MK, Ferreira Rocha NB, Paes F, Oliveira AC, et al. Potential therapeutic effects of 
physical exercise for bipolar disorder. CNS Neurol Disord Drug Targets. 2015;14:1255-9.

11. Wrann CD, White JP, Salogiannnis J, Laznik-Bogoslavski D, Wu J, Ma D, et al. Exercise induces hippocampal BDNF through a PGC1a/FNDC5 pathway. Cell Metab. 2013;18:649-59.

12. Jerome GJ, Young DR, Dalcin A, Charleston J, Anthony C, Hayes J, et al. Physical activity levels of persons with mental illness attending psychiatric rehabilitation programs. Schizophr Res. 2009;108:252-7.

13. Teixeira-Lemos E, Nunes S, Teixeira F, Reis F. Regular physical exercise training assists in preventing type 2 diabetes development: focus on its antioxidant and anti-inflammatory properties. Cardiovasc Diabetol. 2011;10:12.

14. Swift $D L$, Lavie CJ, Johannsen NM, Arena R, Earnest $C P$, O'Keefe $\mathrm{JH}$, et al. Physical activity, cardiorespiratory fitness, and exercise training in primary and secondary coronary prevention. Circ J. 2013;77:281-92.

15. Gomes FA, Almeida KM, Magalhães P V, Caetano SC, KauerSant'Anna M, Lafer B, et al. Cardiovascular risk factors in outpatients with bipolar disorder: a report from the Brazilian Research Network in Bipolar Disorder. Rev Bras Psiquiatr. 2013;35:126-30.

16. Magalhães $P V$, Kapczinski $F$, Nierenberg AA, Deckersbach $T$, Weisinger $D$, Dodd $S$, et al. Illness burden and medical comorbidity in the Systematic Treatment Enhancement Program for Bipolar Disorder. Acta Psychiatr Scand. 2012;125:303-8.

17. Fagiolini A, Forgione R, Maccari M, Cuomo A, Morana B, Dell'Osso $M C$, et al. Prevalence, chronicity, burden and borders of bipolar disorder. J Affect Disord. 2013;148:16-9.

18. Sierra P, Livianos L, Arques S, Castelló J, Rojo L. Prodromal symptoms to relapse in bipolar disorder. Aust N Z J Psychiatry. 2007;41:385-91.

19. Swartz HA, Fagiolini A. Cardiovascular disease and bipolar disorder: risk and clinical implications. J Clin Psychiatry. 2012;73:1563-5.

20. Kupfer DJ. The increasing medical burden in bipolar disorder. JAMA. 2005;293:2528-30.

21. Compton MT, Daumit GL, Druss BG. Cigarette smoking and overweight/obesity among individuals with serious mental illnesses: a preventive perspective. Harv Rev Psychiatry. 2006:14:212-22.

22. Park A-L, McDaid D, Weiser P, Von Gottberg C, Becker T, Kilian $R$. Examining the cost effectiveness of interventions to promote the physical health of people with mental health problems: a systematic review. BMC Public Health. 2013;13:787.

23. Sylvia LG, Nierenberg AA, Stange JP, Peckham AD, Deckersbach T. Development of an integrated psychosocial treatment to address the medical burden associated with bipolar disorder. J Psychiatr Pract. 2011;17:224-32.

24. Booth ML, Bauman A, Owen N, Gore CJ. Physical activity preferences, preferred sources of assistance, and perceived barriers to increased activity among physically inactive Australians. Prev Med (Baltim). 1997;26:131-7.

25. Vancampfort D, Correll CU, Probst M, Sienaert P, Wyckaert S, De Herdt $A$, et al. A review of physical activity correlates in patients with bipolar disorder. J Affect Disord. 2013;145:285-91.

26. Salmon J, Owen N, Crawford D, Bauman A, Sallis JF. Physical activity and sedentary behavior: a population-based study of barriers, enjoyment, and preference. Health Psychol. 2003;22:178-88.

27. Roberts SH, Bailey JE. Incentives and barriers to lifestyle interventions for people with severe mental illness: a narrative synthesis of quantitative, qualitative and mixed methods studies. J Adv Nurs. 2011;67:690-708.

28. Ussher M, Stanbury L, Cheeseman V, Faulkner G. Physical activity preferences and perceived barriers to activity among persons with severe mental illness in the United Kingdom. Psychiatr Serv. 2007;58:405-8.

29. McDevitt J, Snyder M, Miller A, Wilbur J. Perceptions of barriers and benefits to physical activity among outpatients in psychiatric rehabilitation. J Nurs Scholarsh. 2006;38:50-5.
30. Fassinger RE. Paradigms, praxis, problems, and promise: Grounded theory in counseling psychology research. J Couns Psychol. 2005;52:156-66.

31. Fogarty $M$, Happell B. Exploring the benefits of an exercise program for people with schizophrenia: a qualitative study. Issues Ment Health Nurs. 2005;26:341-51.

32. Tetlie T, Heimsnes MC, Almvik R. Using exercise to treat patients with severe mental illness. J Psychosoc Nurs Ment Health Serv. 2009;47:32-40.

33. American Psychiatric Association's Task Force on Research Ethics. Ethical principles and practices for research involving human participants with mental illness. Psychiatr Serv. 2006;57:552-7.

34. Curry LA, Nembhard IM, Bradley EH. Qualitative and mixed methods provide unique contributions to outcomes research. Circulation. 2009;119:1442-52.

35. Vaismoradi $\mathrm{M}$, Turunen $\mathrm{H}$, Bondas $\mathrm{T}$. Content analysis and thematic analysis: Implications for conducting a qualitative descriptive study. Nurs Health Sci. 2013;15:398-405.

36. Tong A, Sainsbury P, Craig J. Consolidated criteria for reporting qualitative research (COREQ): a 32-item checklist for interviews and focus groups. Int J Qual Heal Care. 2007;19:349-57.

37. DiCicco-Bloom B, Crabtree BF. The qualitative research interview. Med Educ. 2006;40:314-21.

38. Etikan I. Comparison of convenience sampling and purposive sampling. Am J Theor Appl Stat. 2016;5:1.

39. Meyrick J. What is good qualitative research? A first step towards a comprehensive approach to judging rigour/quality. J Health Psychol. 2006;11:799-808.

40. Corbin J, Strauss A. Basics of qualitative research: techniques and procedures for developing grounded theory. 4th ed. Thousand Oaks: Sage Publications; 2008.

41. Pope C, Mays N. Qualitative research in health care. 3th ed. London: BMJ Books; 2006.

42. Nayar S. Grounded theory: a research methodology for occupational science. J Occup Sci. 2012;19:76-82.

43. QSR International Pty LTD. NVivo qualitative data analysis software. Doncaster: QSR International Pty Ltd; 2010.

44. Vancampfort D, Stubbs B, Ward PB, Teasdale S, Rosenbaum S. Integrating physical activity as medicine in the care of people with severe mental illness. Aust New Zeal J Psychiatry. 2015;49:6812.

45. Michalak EE, Yatham LN, Maxwell V, Hale S, Lam RW. The impact of bipolar disorder upon work functioning: a qualitative analysis. Bipolar Disord. 2007; 9:126-43

46. Cairney J, Veldhuizen S, Faulkner G, Schaffer A, Rodriguez MC. Bipolar disorder and leisure-time physical activity: Results from a national survey of Canadians. Ment Health Phys Act. 2009;2:65-70.

47. Graham C, Rollings C, de Leeuw S, Anderson L, Griffiths B, Long N. A qualitative study exploring facilitators for improved health behaviors and health behavior programs: mental health service users' perspectives. Sci World J. 2014;2014:1-7.

48. Hanson S, Jones A. A spatial equity analysis of a public health intervention: a case study of an outdoor walking group provider within local authorities in England. Int J Equity Health. 2015;14:106.

49. Poirier J, Bennett WL, Jerome GJ, Shah NG, Lazo M, Yeh H-C, et al. Effectiveness of an activity tracker- and Internet-based adaptive walking program for adults: a randomized controlled trial. J Med Internet Res. 2016;18:e34.

50. Lee I-M, Buchner DM. The importance of walking to public health. Med Sci Sports Exerc. 2008;40(7 Suppl):S512-8.

\section{Correspondence:}

\section{Pedro V.S. Magalhães}

Laboratório de Psiquiatria Molecular, Universidade Federal do Rio Grande do Sul

Rua Ramiro Barcelos, 2350

90035-903 - Porto Alegre, RS - Brazil

Tel.: +55 (51) 33598845, Fax: +55 (51) 33598846

E-mail: pedromaga2@gmail.com 